\title{
TURISMO NO PANTANAL/MS: ENTRE A PANDEMIA DA COVID-19 E AS QUEIMADAS
}

\author{
TOURISM IN PANTANAL / MS: BETWEEN THE PANDEMIC OF COVID-19 AND THE BUSHFIRES
}

TURISMO EN PANTANAL / MS: ENTRE LA PANDEMIA DE COVID-19 Y LOS INCENDIOS

\section{RESUMO}

Em março de 2020 a Organização Mundial da Saúde - OMS reconheceu a situação de pandemia da Covid-19, em função das altas taxas de disseminação, provocando a paralização de setores econômicos, sociais e culturais, representativos. 0 processo de readequação à realidade posta instigou um grupo de pesquisadoras do turismo a compreender os mecanismos advindos desse período histórico e social. Este artigo tem como objetivo apresentar um diagnóstico dos impactos da pandemia pela Covid-19 no Pantanal de Mato Grosso do Sul, a partir da análise comparativa dos dados referentes ao ano de 2019 e 2020. Em associação à atividade turística nas cidades de Aquidauana, Corumbá e Miranda - delimitação espacial da investigação e às intensas queimadas que assolaram o Pantanal em 2020. A metodologia envolveu análise comparativa de dados da cadeira produtiva do turismo, além do levantamento bibliográfico, documental e entrevistas com agentes públicos e privados do turismo. Tanto a pandemia quanto as queimadas contribuíram para a diminuição do turismo no Pantanal, o qual, após a adoção de medidas de biossegurança definidas pela OMS, apresenta uma movimentação lenta e gradual a partir de pequenos deslocamentos, ou seja, um crescimento do turismo local, considerando que os/as empresários/as e trabalhadores/as do turismo estão se organizando para a retomada da atividade, com a recuperação do ambiente e ao mesmo tempo se adequando as medidas de biossegurança.

Palavras-chave: Pantanal. Pandemia. COVID-19. Turismo. Queimadas.

\section{ABSTRACT}

In March 2020, the World Health Organization - WHO recognized the Covid-19 pandemic situation, due to the high spread rates of the disease, causing the paralysis of representative economic, social and cultural sectors. The process of readjusting to reality prompted a group of researchers on tourism to understand the mechanisms arising from this historical and social period. This article aims to provide a diagnosis of the impacts of the pandemic by Covid-19 in the Pantanal of Mato Grosso do Sul, based on a comparative analysis of data for the years of 2019 and 2020, associated with tourism in the cities of Aquidauana, Corumbá and Miranda - spatial delimitation of the investigation - and the intense bushfires that devastated the Pantanal in 2020. The methodology involved a comparative analysis of data from the productive sector of tourism, bibliographical, documentary survey, and interviews with public and private tourism agents. The pandemic and the bushfires contributed to a decrease in tourism in the Pantanal, but, after the adoption of biosafety measures by the WHO, shows a slow and gradual movement with small displacements, that is, an increase in local tourism, businessmen and tourism workers are organizing themselves for the resumption of activity, with the recovery of the environment and at the same time adapting the biosafety measures.

Keywords: Pantanal. Pandemic. COVID-19. Tourism. Bushfire.

\section{RESUMEN}

En marzo de 2020, la Organización Mundial de la Salud - OMS reconoció la situación de la pandemia de Covid-19, debido a las altas tasas de dispersión, provocando la parálisis de sectores económicos, sociales y culturales representativos. El proceso de readaptación a la realidad actual impulsó a un grupo de investigadores en turismo a comprender los mecanismos derivados de este período histórico y social. Este artículo tiene como objetivo presentar un diagnóstico de los impactos de la
Mara Aline Ribeiro ${ }^{a}$

Karoline Batista Gonçalves ${ }^{b}$

Joyce Avila de Oliveira ${ }^{b, c}$

${ }^{a}$ Universidade Federal de Mato Grosso do Sul (UFMS), Campo Grande, MS, Brasil

${ }^{\text {b }}$ Universidade Federal da Grande Dourados (UFGD), Dourados, MS, Brasil

${ }^{\mathrm{c}}$ Instituto Federal de Mato Grosso do Sul (IFMS), Jardim, MS, Brasil

DOI: 10.12957/geouerj.2021.61341

Correpondência: mara_aline@yahoo.com.br

Recebido em: 19 mar. 2021 Aceito em: 1 jul. 2021 
pandemia Covid-19 en el Pantanal de Mato Grosso do Sul, a partir de un análisis comparativo de datos para los años 2019 y 2020. Asociados al turismo en las ciudades de Aquidauana, Corumbá y Miranda - delimitación espacial de la investigación - y los intensos incendios que devastaron el Pantanal en 2020. La metodología implica el análisis comparativo de datos del sector productivo turístico, encuestas bibliográficas y documentales y entrevistas con agentes turísticos públicos y privados. La pandemia y los incendios contribuyeron a la disminución del turismo en el Pantanal, pero, después de la adopción de las medidas de bioseguridad definidas por la OMS, muestra un movimiento lento y paulatino con pequeños desplazamientos, es decir, un incremento del turismo local, los empresarios y trabajadores del turismo se están organizando para la reanudación de la actividad, con la recuperación del medio ambiente y, al mismo tiempo, adaptando las medidas de bioseguridad.

Palabras-clave: Pantanal. Pandemia. COVID-19. Turismo. Incendios Florestales. 


\section{INTRODUÇÃO}

A pandemia da COVID-19 assolou o mundo inteiro no ano de 2020 e assim se mantém nesse primeiro semestre de 2021. Todas as esferas econômicas, sociais e culturais, em âmbito planetário, tiverem impactos negativos. A atividade turística, enquanto um setor da economia que envolve circulação de pessoas, foi uma das primeiras atividades interrompidas diante da ordem mundial de retração.

Em uma rápida retrospectiva, as imagens que vêm à mente são de aeronaves no solo, ônibus nas garagens, hotéis e pousadas fechadas, eventos cancelados, pacotes de viagem suspensos, agências e operadoras de turismo em stand by, além de desemprego e perda de muitos postos de trabalho da cadeia produtiva do turismo. Trata-se de um cenário mundial desolador. Segundo dados do IBGE (2020) referentes às atividades turísticas, houve uma perda de 36,7\% em volume de serviços prestados em 2020.

O quadro estatístico se reproduz no estado de Mato Grosso do Sul, o qual conta com 8 regiões turísticas, distribuídas em 42 municípios, de acordo com o Mapa Turístico do MS (2019) ${ }^{1}$, sendo elas: Caminho dos Ipês, Bonito/ Serra da Bodoquena, Grande Dourados, Costa Leste/ Vale do Aporé, Vale das Águas, Caminhos da Natureza/Cone Sul e o Pantanal.

A análise deste estudo se pautou em observar a porção sul do Pantanal, conhecida pela exuberância da fauna e da flora e pela piscosidade dos rios da Bacia do Alto Pantanal, por ser um lugar receptor de turistas nacionais e internacionais e por apresentar uma das maiores taxas de dependência do turismo, baseada em número de estabelecimentos, de empregos e massa salarial. Além disso, excepcionalmente, nos anos de 2019 e 2020 a região sofreu os impactos de um período de seca extrema, acompanhado por queimadas em toda extensão do recorte espacial da pesquisa.

O Pantanal é um ambiente transfronteiriço localizado na América do Sul e abrange uma área que abarca Bolívia, Brasil e Paraguai. No Brasil, está localizado na região centro-oeste entre os estados de Mato Grosso e Mato Grosso do Sul, com uma área de 151.134 km² (IBGE, 2017).

Conforme Gonçalves (2019), o Pantanal pode ser visto como uma conexão entre o Cerrado Brasileiro, o Chaco Boliviano e Paraguaio e a Amazônia, tornando esse ambiente um elo para os demais. Por se tratar de um ecossistema extremamente complexo, foram estabelecidas sub-regiões, levando em consideração os rios que banham a planície e a geomorfologia. São chamadas de pantanais do Aquidauana, Miranda, Rio Negro, Taboco, Nhecolândia, Abobral, Nabileque, Poconé, Paraguai e Paiaguás, distribuídas entre os municípios de Aquidauana, Miranda, Corumbá, Ladário, Porto Murtinho, Coxim, Rio Verde, Sonora, Bodoquena, Jardim e 
Bonito, sendo os quatros últimos considerados peripantaneiros, porque estabelecem relações vitais com os demais.

No ano 2000 a UNESCO concedeu ao Pantanal o título internacional de Reserva do Patrimônio Mundial e Sítio RAMSAR - Convenção sobre Zonas Úmidas de Importância Internacional, especialmente como Habitat de Aves Aquáticas - conferidos à área do Parque Nacional Pantanal Mato-grossense em 1993 e Reserva da Biosfera Mundial no ano 2000 (UNESCO, 2000).

No Mato Grosso do Sul, o Pantanal ocupa um papel de destaque porque possui três importantes segmentos turísticos para o desenvolvimento e expansão da atividade, o turismo de pesca esportiva, o turismo contemplativo e, mais recentemente, o turismo de observação de aves, que atraem anualmente milhares de turistas interessados/as em conhecer a diversidade ambiental do estado.

A infraestrutura para atender os/as turistas de pesca é composta por barcos-hotéis, embarcações de pequeno, médio e grande porte, ranchos de pesca e pousadas. O turismo contemplativo é praticado, sobretudo, por estrangeiros/as e conta com infraestrutura de diversas categorias, de pousadas com instalações mais rústicas, para receber uma clientela chamada alternativa, até pousadas e hotéis fazendas para turistas com alto poder aquisitivo. Com diferentes equipamentos e comodidades, os roteiros são semelhantes, como, por exemplo, cavalgada, passeios noturnos, dia de campo, observação de felinos e aves, distinguindo, basicamente, os valores e as comodidades.

Os empreendimentos contam ainda com uma equipe de profissionais em constante processo de qualificação para recepcionar integralmente os/as turistas durante a estada no Pantanal e normalmente ocupam variadas funções, como, por exemplo, monitores ambientais, cozinheiras, guias de turismo, serviços gerais, piloteiros, camareiras e garçons.

Parte desses trabalhadores (sessenta e dois por cento dos trabalhadores do turismo entrevistados) adentraram terras pantaneiras juntamente com os proprietários dos empreendimentos turísticos e constituem o grupo das novas gentes pantaneiras atraídos pelo desenvolvimento da atividade turística (RIBEIRO, 2015, p. 52).

Nesse período de pandemia, toda a cadeia produtiva do turismo está sofrendo as implicações da paralisação da atividade e com um agravante a mais, as queimadas que atingiram $30 \%$ do território pantaneiro (NOLEEDI, 2020).

Para conhecer a dimensão dos efeitos da pandemia na região pantaneira, esse artigo tem como objetivo apresentar um diagnóstico dos impactos da pandemia pela Covid-19 no Pantanal de Mato Grosso do Sul, a partir da análise comparativa dos dados referentes aos anos de 2019 e 2020 . O recorte territorial no qual se pautou a análise foi o Pantanal sul-mato-grossense, especialmente três municípios: Aquidauana, Corumbá e 
Miranda, elencados pela relevância das atividades turísticas, por receberem maior número de turistas brasileiros/as e estrangeiros/as no estado. A Figura 1 permite observar a extensão do Pantanal no Brasil, bem como as cidades analisadas:

Figura 1. Mapa de localização do Pantanal e dos municípios analisados. Fonte: Elaborado pelas autoras com base IBGE (2021); DIVAGIS (2021)

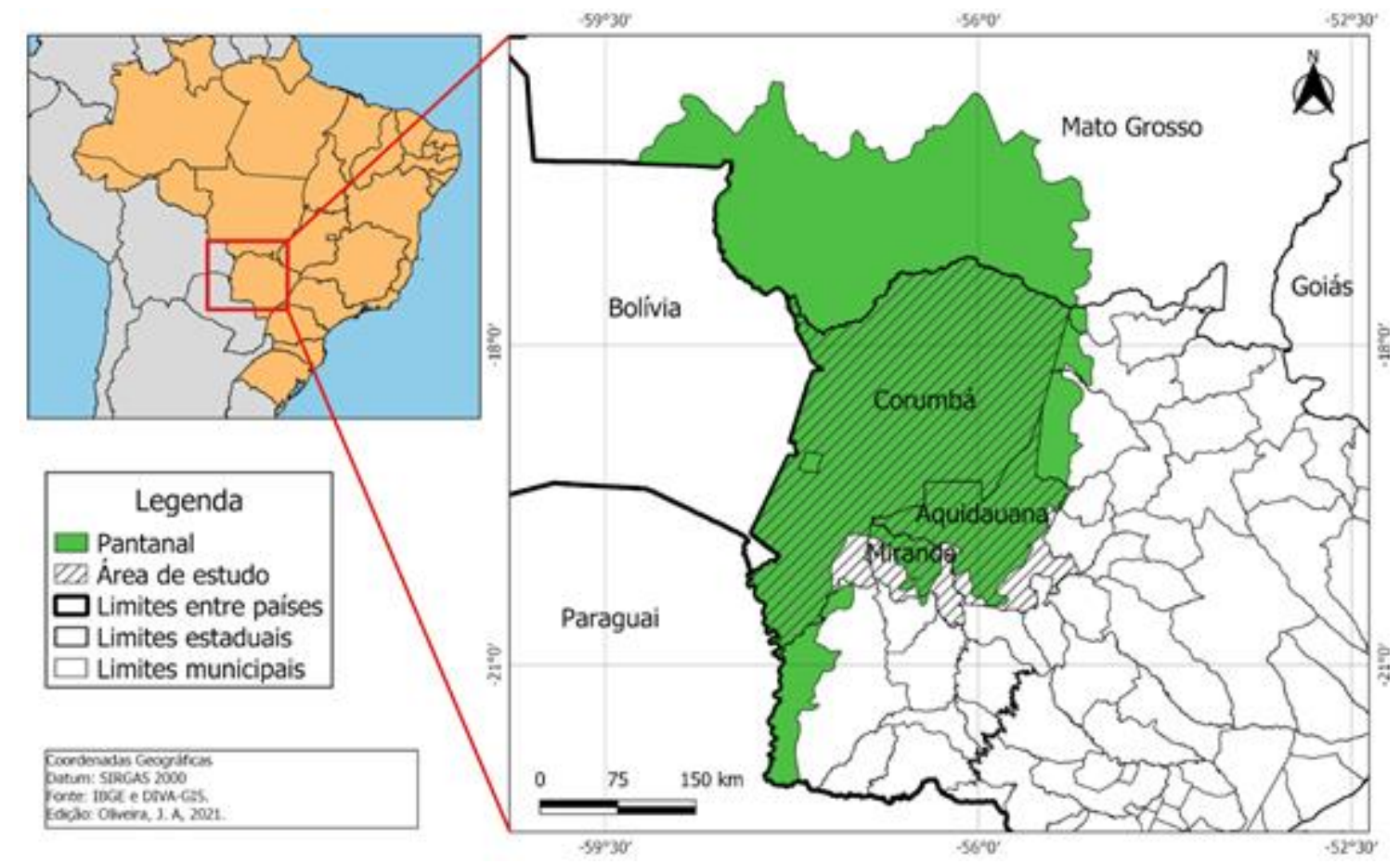

Os procedimentos metodológicos adotados foram a pesquisa bibliográfica e documental, sendo a última realizada a partir do levantamento de dados em sites dos órgãos oficiais de turismo das prefeituras municipais, da Associação Brasileira da Indústria de Hotéis - ABIH, da Associação Brasileira de Agências de Viagens - ABAV, Instituto Brasileiro de Geografia e Estatística - IBGE, Fundação de Turismo de Mato Grosso do Sul, Observatório do Turismo de Mato Grosso do Sul, Cadastro Geral de Empregados e Desempregados - CAGED, Novo CAGED e de outras instituições. Pela impossibilidade de executar o trabalho de campo in loco, foram realizadas entrevistas via telefone, e-mail e redes sociais, com membros de associações vinculadas ao turismo, empresários do setor e representantes das prefeituras e órgãos oficiais de turismo, com o intuito de obter informações sobre os impactos da pandemia em seus respectivos contextos. Como parte da metodologia, foi estabelecido calendário de reuniões quinzenais para discutir os encaminhamentos da pesquisa, a partir das orientações do chamado grupo de metodologia, ordenado pela coordenação da pesquisa "Turismo em tempos de pandemia: uma abordagem geográfica multi e trans-escalar", do qual as pesquisadoras fazem parte.

O referencial teórico se apoia na ciência geográfica e utiliza de outras ciências - como, a estatística, o turismo e a economia - para ajudar a compreender a pandemia como um elemento reorganizador da atividade 
turística no cenário mundial. As atividades turísticas do Pantanal sul-mato-grossense enfrentaram, durante o ano de 2020, impactos gerados a partir das restrições de viagens, fechamento de fronteiras, medidas restritivas e de isolamento social. Nesse momento, duas vertentes se destacaram: a pandemia da COVID-19 e as queimadas.

Entre a COVID-19 e as queimadas: a resistência da atividade turística no Pantanal/MS

O novo agente do coronavírus, causador da COVID-19, foi descoberto em 31 de dezembro de 2019, após casos registrados na China, e passou a ser considerado pandemia em março de 2020 pela Organização Mundial da Saúde 2 . Os primeiros casos de COVID-19 no estado do Mato Grosso do Sul foram confirmados pela Secretaria Estadual de Saúde - SES no dia 14 de março de 2020, ambos na capital Campo Grande. Na segunda quinzena do mesmo mês, a Assembleia Legislativa decretou estado de calamidade com efeitos até 31 de dezembro de 2020 e, como medida sanitária, na capital foi instalado um controle sanitário no Aeroporto Internacional de Campo Grande.

Especificamente para os municípios definidos para este ensaio, os primeiros casos de COVID-19 em Corumbá e Miranda foram confirmados no mês de abril, mesmo período em que iniciam as atividades do Drive-Thru em Corumbá, cujo objetivo era fazer a testagem das pessoas por meio de agendamento prévio. Concomitantemente, a Secretaria de Estado de Saúde do MS alertou para interiorização do coronavírus, onde houve o crescimento exponencial na incidência de casos. O município de Aquidauana confirmou o primeiro caso de infecção somente no mês de junho de 2020.

Segundo Boletim Epidemiológico do MS de 01 de janeiro de 2020, o aumento dos números de casos ocorreu em julho, com pico em agosto, após este período houve uma redução até o mês de novembro. Em dezembro foi registrado o maior número de casos, com os maiores números de óbitos no MS, agosto registrou 488 óbitos e dezembro 552.

De acordo com a ONG Ecologia e Ação - ECOA (2020) no que diz respeito ao número de pessoas contaminadas em Corumbá em dezembro de 2020, as comunidades com mais casos notificados foram: Distrito de Albuquerque (13), Comunidade Maria Coelho (14), Assentamento São Gabriel (12) e Assentamento Taquaral (10). Esse aumento no número de casos se deve ao fato de que com o fim da temporada de pesca, muitas famílias buscam a cidade de Corumbá para receber o Seguro Desemprego do Pescador Artesanal, conhecido como "Seguro Defeso".

\footnotetext{
2 Disponível em: https://www.coronavirus.saude.gov.br/linha-do-tempo/

${ }^{3}$ O defeso é a paralisação temporária da pesca para a preservação das espécies, em consequência da reprodução. O Seguro Defeso é o benefício pago ao pescador profissional que fica proibido de exercer a atividade pesqueira durante o período da piracema.
} 
Na região pantaneira, o Setor Privado do Turismo abrange pousadas, barcos-hotéis, restaurantes, hotéis, agências de turismo, o qual passou por uma representativa retração nos primeiros meses da pandemia, quando a atividade turística no MS foi interrompida oficialmente, por intermédio de Decretos Municipais, durante aproximadamente 90 dias, com pequenas variações entre uma cidade e outra. Imediatamente, o empresariado sentiu a redução na receita/faturamento das empresas, com a diminuição na taxa de ocupação dos hotéis, de cerca de $50 \%$ em relação ao mesmo período de 2019 , consequentemente houve perdas nos postos de trabalho, segundo informações do trade turístico.

Para contornar os impactos causados pela COVID-19, os/as empresários/as, entrevistados/as, estão adotando novas medidas de biossegurança e projetos no intuito de diminuir os prejuízos advindos da redução e/ou cancelamento das atividades, como é possível observar no relato a seguir:

\begin{abstract}
Eu sou guia local aqui em Aquidauana e trabalho com camping, trilha e rapel, e também com agricultura familiar. No setor do turismo tivemos que fazer nossas restrições, para cuidar da nossa saúde, porque o turista nem sempre ficou em casa como era pra ser feito. A prefeitura teve que intervir colocando barreiras sanitárias nas entradas da cidade para controle da Covid-19. Aqui nós desenvolvemos um questionário para o turista, para saber o destino e de onde vieram, caso ocorresse algum caso após a visita, tinha como identificar o turista e ao mesmo tempo avisar para procurar a unidade de saúde. No nosso caso, estamos correndo atrás de outras alternativas para enfrentar os prejuízos como: venda de doce de leite, queijo artesanal, para melhorar a renda e suprir as necessidades, não podemos ficar dependendo só do governo, tem que correr atrás também. O governo tem que priorizar em atender os doentes e conseguir logo a vacina. A prefeitura tem nos apoiado. Falta melhorar as vias de acesso. Mais manutenção nas estradas (Entrevista com Guia Local de Aquidauana realizada em 23/11/2020)4.
\end{abstract}

Em relação ao número de empregos com carteira assinada nas Atividades Características do Turismo ACTs obtidas através do CAGED (2019) e Novo CAGED (2020), se percebe que todos os municípios considerados neste estudo apresentaram menos admissões em relação ao primeiro semestre do ano anterior, Aquidauana (-15), Corumbá (-174) e Miranda (-41). Quanto aos desligamentos, apenas em Corumbá (-33) o número de pessoas que perderam o emprego foi maior que no mesmo período do ano anterior. O número de desligamentos nos municípios de Aquidauana (+9) e Miranda (+21) foi menor que no primeiro semestre de 2019 (CAGED, 2019 e Novo CAGED, 2020), como se observa no Quadro 1.

Quadro 1. Número de empregos nas atividades características do turismo ${ }^{5}$. Fonte: CAGED, 2019 e Novo CAGED, 2020

\begin{tabular}{|c|c|c|c|}
\hline \multirow{2}{*}{ Município } & Movimentação & \multicolumn{2}{|c|}{ Janeiro a Junho } \\
\cline { 3 - 4 } & Admissão/Desligamento & $\mathbf{2 0 1 9}$ & $\mathbf{2 0 2 0}$ \\
\hline \multirow{2}{*}{ Aquidauana } & Admissão & 50 & 35 \\
\cline { 2 - 4 } & Desligamento & 43 & 34 \\
\hline
\end{tabular}

\footnotetext{
${ }^{4}$ As entrevistas foram reproduzidas na íntegra, os nomes, omitidos para preservar a identidade das pessoas entrevistadas estão nos arquivos das autoras.

${ }^{5}$ As classes do CNAE 2.0 consideradas como Atividades Características do Turismo foram: hotéis e similares, outros tipos de alojamento não especificados anteriormente, restaurantes e outros estabelecimentos de serviços de alimentação e bebidas, locação de automóveis sem condutor, agências de viagens, operadores turísticos, serviços de reservas e outros serviços de turismo não especificados anteriormente, atividades de organização de eventos, exceto culturais e esportivos.
} 


\begin{tabular}{|c|c|c|c|}
\hline \multirow{2}{*}{ Corumbá } & Admissão & 301 & 127 \\
\cline { 2 - 4 } & Desligamento & 157 & 190 \\
\hline \multirow{2}{*}{ Miranda } & Admissão & 78 & 37 \\
\cline { 2 - 4 } & Desligamento & 69 & 48 \\
\hline
\end{tabular}

Frente ao cenário de incertezas, o auxílio emergencial aparece como uma possibilidade de reduzir o impacto da pandemia na economia. Instituído pela Lei de no 13.982/2020, o benefício é direcionado para contribuintes individuais do Instituto Nacional do Seguro Social - INSS, trabalhadores de baixa renda, informais e microempreendedores individuais. Entre os meses de abril e agosto, o número de pessoas beneficiadas, considerando o recorte desta pesquisa, foi aumentando progressivamente, apresentando uma queda mais abrupta no mês de junho e posteriormente uma diminuição no mês de agosto. Os principais motivos dos/as trabalhadores/as recorreram ao auxílio emergencial é a impossibilidades de desenvolver ACTs e o desemprego.

Por se tratar de um vírus infectocontagioso para os seres humanos e transmitido por aerossóis tornando a sua dispersão facilitada, imediatamente a circulação de turistas pode ser associada à disseminação do novo coronavírus, tanto que entre as primeiras medidas está a suspensão de voos, a partir da adoção dos protocolos de segurança orientados pela Organização Mundial de Saúde - OMS. Em um mundo globalizado, a circulação de capital e de pessoas é constante, transformando os meios de transporte e os deslocamentos em rotas de dispersão do vírus. Os impactos do fechamento das fronteiras entre países e do esvaziamento dos aeroportos são significativos no impacto da economia, porém, de extrema importância para a diminuição da proliferação do Sars-CoV-2.

Conforme apontado por Spósito e Guimarães (2020), as interações espaciais não compreendem apenas a natureza territorial, mas também as interações espaciais imateriais, considerando o uso das tecnologias de comunicação e informação. Nesse contexto, as ações para entender a articulação do sistema de objetos refletem na dinâmica espacial, porque a falta de esclarecimento para a população mundial sobre a COVID-19 e as medidas de prevenção, sobretudo das populações mais vulneráveis, não é uma particularidade da região pantaneira, onde, pela simples ausência da rede de energia elétrica em toda a região do Pantanal, mantém uma parcela da comunidade local em isolamento social muito antes do advento da pandemia.

É possível fazer uma comparação que demonstra as mudanças nas perspectivas de mobilidade espacial e concentração no espaço geográficos, principalmente nos centros urbanos, utilizando a ocorrência e o desenvolvimento, no início do século XX, da Gripe Espanhola, quando a cidade de Corumbá, na época como parte do território do Mato Grosso, em três meses registrou o maior número de mortes do estado, 160 vítimas das 700 registrada no estado (Costa, 2020). Ainda, segundo a autora, os jornais locais da época atribuíram a circulação do vírus às embarcações que chegaram ao porto de Corumbá. Na tentativa de conter a epidemia, 
foi instalado um posto sanitário às margens do rio Paraguai para inspecionar os navios da rota compreendida desde a capital Cuiabá até a cidade do Rio de Janeiro.

Na pandemia da COVID-19, as vias marítimas, aeroportuárias e rodoviárias são exímios caminhos de circulação e disseminação do vírus, tanto que a cidade Corumbá tem altos índices de contaminação pelo coronavírus no estado.

Quanto ao fluxo turístico no Mato Grosso do Sul, ainda no primeiro trimestre de 2020, ocorreu uma redução de $-1,67 \%$, inferido que $51,78 \%$ das pessoas desembarcadas no MS eram turistas, sendo que Corumbá era a cidade de destino de $7,32 \%$ dos desembarques no estado (OBSERVATÓRIO DO TURISMO, 2020). A movimentação rodoviária em março do mesmo ano apresentou uma redução de $-36,99 \%$, na variação percentual. 0 mesmo ocorreu com os fretamentos turísticos que sofreram uma retração de $-47,38 \%$ no número de passageiros/as (OBSERVATÓRIO DO TURISMO, 2020).

Mesmo com a diminuição na circulação de pessoas pelos aeroportos e rodoviárias no mundo todo, no Pantanal a dinâmica foi relativamente diferenciada. Motivados/as pelo lazer e pela inerente necessidade de "fugir" da estafante rotina em tempos de pandemia, turistas, sobretudo do estado, se aventuraram por terras pantaneiras em veículos próprios, realizando pequenos deslocamentos e pernoitando em campings em busca de um reencontro com o ambiente natural.

\footnotetext{
Sendo assim, entende-se que o fechamento temporário de aeroportos e rodoviárias não impediu a circulação de pessoas motivadas pelo lazer. Tampouco houve fiscalização eficiente e rigorosa ao longo da Estrada-Parque Pantanal que dá acesso às pousadas e aos ranchos de pesca. Logo, há uma contradição entre a fala do pantaneiro e as informações dos órgãos oficiais do turismo (RIBEIRO e NOVAES, 2020, p.184).
}

Em meio ao enfrentamento de um vírus ainda pouco conhecido pela ciência, o Pantanal ardeu em chamas nos anos de 2019 e 2020, em uma proporção muito maiores do que as registradas pelo Instituto Nacional de Pesquisas Espaciais - INPE em anos anteriores, as quais não chegavam a representar prejuízos para a atividade turística.

Os incêndios florestais no bioma Pantanal apresentam os maiores registros de focos de calor desde 1998, quando se iniciou o monitoramento pelo Instituto Nacional de Pesquisas Espaciais (Inpe). Antes de 2020 o ano com maior registro de focos de calor para o bioma foi o ano de 2005 (NOLEEDI, 2020).

Intensas queimadas devastaram extensas áreas dos municípios pantaneiros delimitados, provocando prejuízos incalculáveis, porque o turismo na região depende, exclusivamente, de boas condições ambientais para acontecer. Nas Figuras 02, 03 e 04, é possível observar o grau de destruição das queimadas, interferindo diretamente na prática do turismo. 
Figura 2. Ponte de Madeira na estrada-parque Pantanal. Fonte: RIBEIRO, M. A. (2018)

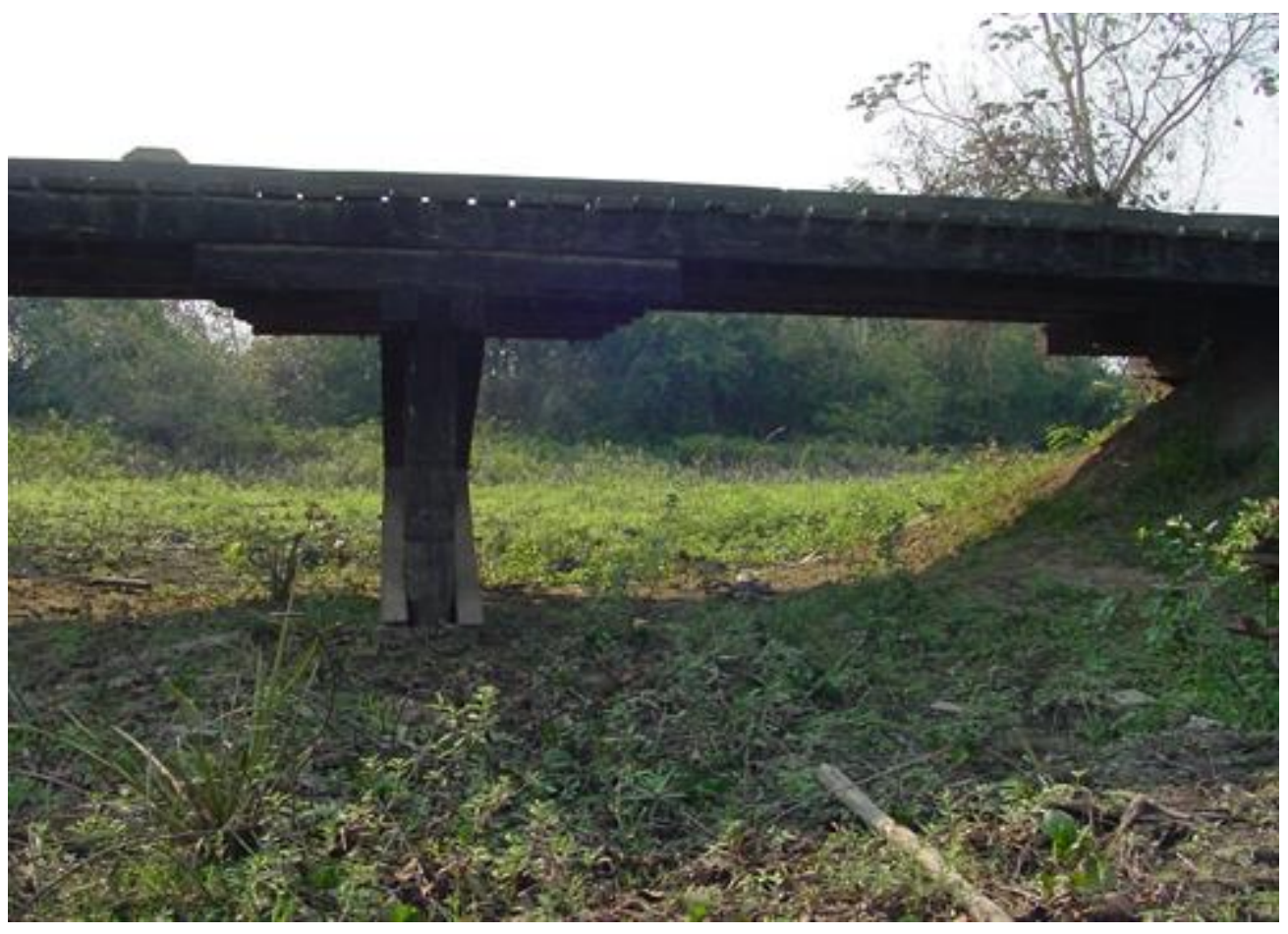

Figura 3. A mesma ponte de madeira da Figura 02 após o início da queimada. A seta indica um veículo que caiu no vão da ponte em meio à fumaça. Fonte: MARCELO, L. F. (2020)

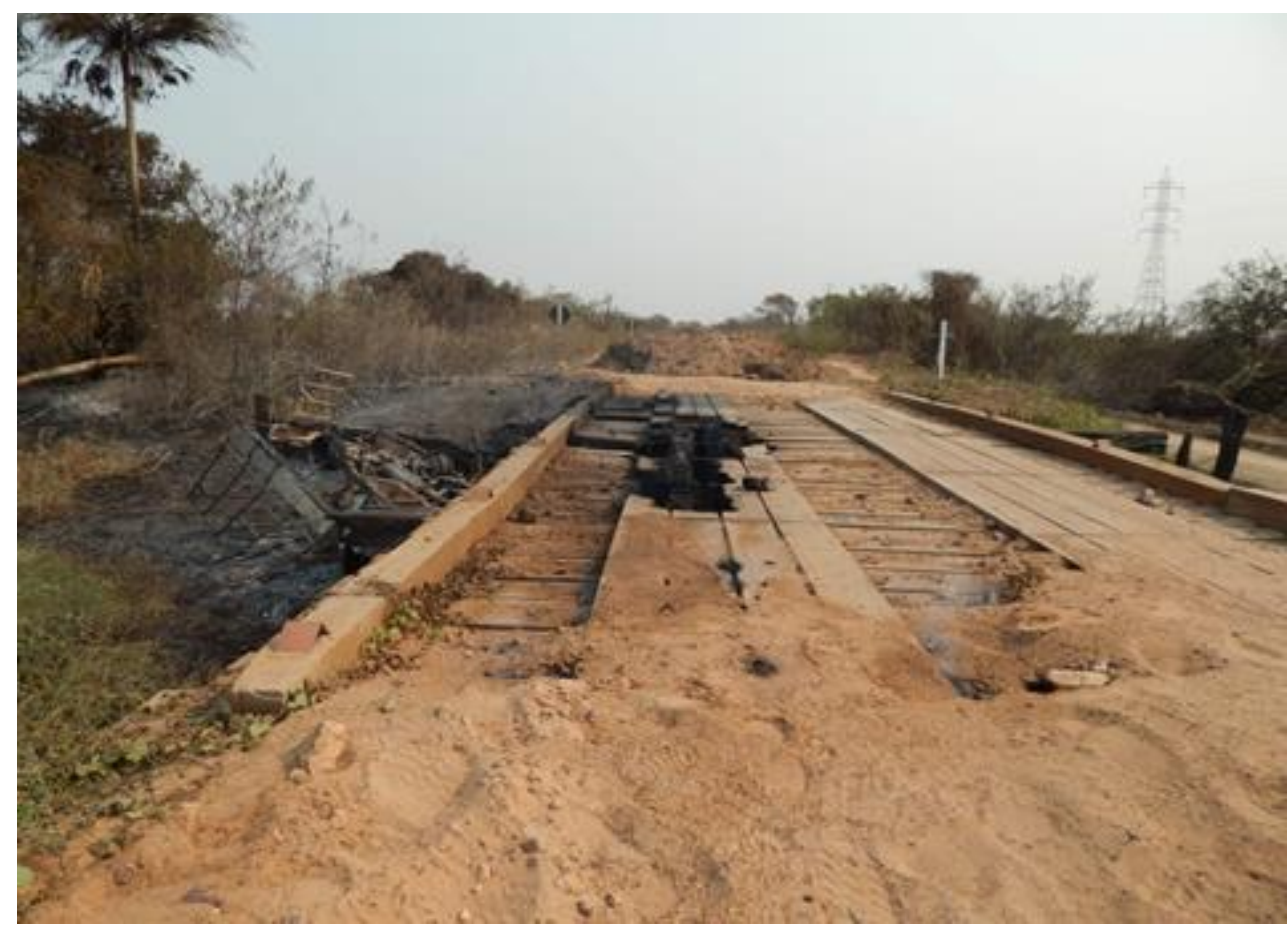


Figura 4. A mesma ponte de madeira das Figura 02 e 03 totalmente destruída pelo fogo. No detalhe o veículo de turismo indicado na Figura 03. Fonte: RIBEIRO, M. A. (2020)

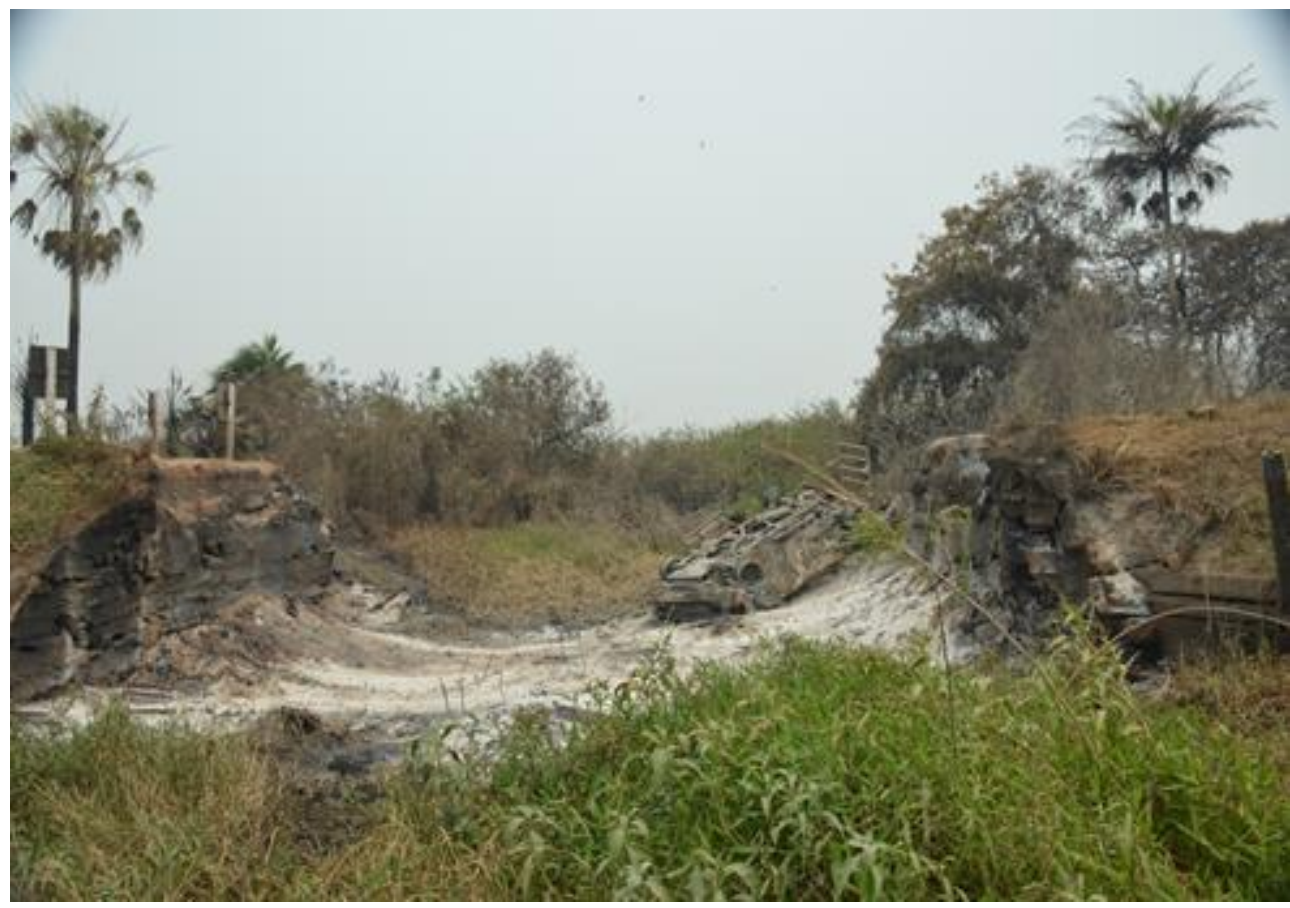

A despeito da recuperação da cobertura vegetal, quase imediata após as primeiras chuvas, em 2020 o fogo atingiu camadas mais profundas do solo, comprometendo recuperação de algumas espécies da flora, interrompendo o importante ciclo de reprodução dos animais que compõem a exuberância local. Além dos prejuízos ao domínio natural do Pantanal, as vias de acesso para as fazendas, as pousadas, as comunidades ribeirinhas, quilombolas e indígenas foram prejudicadas, justamente devido à queima de pontes.

Os prejuízos na infraestrutura, provocados pelas queimadas, foram mais representativos em 2020 em comparação ao mesmo período de 2019 , com dezenas de pontes queimadas e, até que sejam reformadas e/ou reconstruídas, a circulação de veículos pelas estradas locais fica prejudicada, não estagnada porque foram abertos caminhos alternativos. Porém, o ambiente pantaneiro, o principal atrativo turístico da região, se recupera, relativamente, rápido das queimadas.

De acordo com o Observatório Pantanal (2020), as queimadas no Pantanal ganharam destaque no cenário nacional e internacional, pelo fato dos impactos gerados terem se estendido para outras regiões do país como, por exemplo, a fumaça produzida pelos incêndios chegaram até o estado do Paraná, cuja distância dos principais focos de incêndio era cerca de 1.4 mil quilômetros. Esta situação se deve à inércia do governo federal em encaminhar equipes do Centro Nacional de Prevenção e Combate aos Incêndios Florestais PREFOGO para o local, pela falta de equipamentos de segurança e de combate ao fogo, pela demora na liberação de recursos para conter os incêndios por parte do governo estadual e, de um modo geral pela impunidade às pessoas que provocaram parte das queimadas. 
A intensidade das queimadas que atingiram, sobretudo, os municípios pantaneiros de Aquidauana, Miranda e Corumbá em 2019 e 2020 emitiram poluentes dos mais diversos, tais como CO2 (dióxido de carbono), o CH4 (metano) e o N2O (óxido nitroso), promotores de infecções respiratórias de todos os níveis na população local. Diante do atual cenário da pandemia da Covid-19, as pessoas adoentadas encontraram dificuldades para ter atendimento na rede de saúde pública, tendo em vista que grande parte dos leitos hospitalares nas cidades de Aquidauana, Corumbá e Miranda, estavam ocupados com doentes graves da Covid-19, segundo informações verbais da representante da Secretaria de Estado de Saúde.

Soma-se aos problemas ambientais e de saúde, a severa diminuição da renda com a piracema na região pantaneira, período de reprodução dos peixes quando a atividade de pesca, seja comercial ou esportiva, fica interrompida nos rios da Bacia do Alto Paraguai entre os meses de novembro e fevereiro (RIBEIRO, 2015). Apesar desse intervalo de tempo estar previsto no calendário de pesca e os/as pescadores/as receberem o Seguro Defeso, em 2020 e 2021 a junção de três fatores - queimadas, pandemia e piracema - potencializaram as perdas econômicas dos/as profissionais do turismo.

Em um esforço coletivo, entidades públicas e privadas em parcerias com ONGs, Universidades, empresários do turismo e da pecuária se uniram em uma ação coletiva para arrecadar recursos com o objetivo de montar brigadas de incêndio em pontos estratégicos da região pantaneira. Os/as profissionais do Corpo de Bombeiro Militar e do PROVFOGO assumirão a responsabilidade de treinar as pessoas que vivem nas comunidades ribeirinhas, fazendas, pousadas, aldeias indígenas e quilombolas, para o enfrentamento aos incêndios no Pantanal, na tentativa de minimizar os impactos ambientais e econômicos provocados pelas queimadas descontroladas como as que aconteceram, principalmente, no último ano.

Considerando a excepcionalidade da pandemia da COVID-19, no último trimestre de 2020, iniciou-se o processo de implantação das medidas de biossegurança da Organização Mundial da Saúde - OMS para o setor turístico. Com os treinamentos oferecidos pelas entidades representativas públicas e privadas, para os/as empresários/as e trabalhadores/as do turismo e a abertura da temporada de pesca em fevereiro de 2021, a expectativa é de uma retomada lenta e progressiva da atividade turística. As perspectivas para o retorno dos/as turistas estrangeiros em terras pantaneiras ainda são a longo prazo, mas a movimentação local já pode ser considerada um alento para quem trabalha com turismo no Pantanal.

É importante lembrar que a cadeia produtiva do turismo composta de pousadas, barcos-hotéis, guias, prestadores de serviços, materiais de pesca, souvenires, dentre outros, pode solicitar auxílio governamental e, assim, garantir renda para os trabalhadores e aporte financeiro para as empresas turísticas a partir do Fundo Geral do Turismo - FUNGETUR, criado pela Medida Provisória no 963 do Ministério do Turismo. 
com o objetivo de minimizar os impactos causados pela pandemia, elabora ações com foco na sensibilização dos turistas e na organização do setor para a retomada segura de todas as atividades (SOUZA; CAMARGO, 2020, p. 17).

Em meio ao caos instaurado na região pantaneira, a comunidade ribeirinha, os/as empresários/as do turismo e da pecuária, em parceria com entidades públicas e privadas, além de universidades e ONGs, lutam para que sejam implementadas políticas públicas de proteção à população local, tanto na questão da saúde coletiva em meio à pandemia, quanto de prevenção e treinamento de equipes de combate a incêndios no Pantanal, responsabilizando criminalmente as pessoas que provocaram as queimadas criminosas e fiscalizando o cumprimento da Lei № $14.021^{6}$ de 07 de julho de 2020 em sua totalidade.

\section{CONSIDERAÇÕES FINAIS}

No ano de 2020, o setor do turismo no Pantanal sul-mato-grossense foi afetado por duas vertentes: as mudanças sociais ocasionadas pela COVID-19, que paralisou por cerca de 90 dias as atividades turísticas desenvolvidas na região, e as queimadas, que destruíram uma parte considerável do ambiente. Ambas reduziram, significativamente, a demanda de turistas e propagou um cenário de dificuldades e desolamento para o funcionamento e manutenção das atividades turísticas na região.

Frente a esse cenário de incertezas, observa-se, nos primeiros meses de 2021, a retomada lenta e gradual da atividade turística no Pantanal, com as empresas características do turismo se reorganizando para o mundo do trabalho, adotando todas as medidas de biossegurança definidas pela OMS, o que implica em uma diminuição no número de turistas e na movimentação financeira do setor, mas aponta para um futuro mais promissor para o turismo.

Somado a isso, percebe-se uma recuperação do ambiente, após o pior episódio de incêndios em décadas. Com o início da estação chuvosa a vegetação está renascendo e boa parte dos animais estão retornando para os seus habitats. Obviamente as perdas na biodiversidade são irreparáveis e os reflexos serão percebidos nas próximas décadas, porém a resiliência da natureza se mostra atuante na Bacia do Alto Paraguai.

No primeiro trimestre de 2021, os sinais de recuperação do turismo no Pantanal têm sido caracterizados por pequenos deslocamentos, com número reduzido de viajantes, evitando contato prolongado, tanto com

\footnotetext{
${ }^{6}$ A Lei № 14.021 de 07 de julho de 2020, dispõe sobre medidas de proteção social para prevenção do contágio e da disseminação da Covid-19 nos territórios indígenas; cria o Plano Emergencial para Enfrentamento à Covid-19 nos territórios indígenas; estipula medidas de apoio às comunidades quilombolas, aos pescadores artesanais e aos demais povos e comunidades tradicionais para o enfrentamento à Covid-19; e visa assegurar aporte de recursos adicionais nas situações emergenciais e de calamidade pública.
} 
moradores/as locais quanto com outros turistas, até que a tão esperada vacina que protege contra o coronavírus seja uma realidade para todos os brasileiros e brasileiras.

Apoiadas no referencial teórico proposto para análise dos dados obtidos nas primeiras etapas da pesquisa "Turismo em tempos de Pandemia", foi possível apresentar o diagnóstico dos impactos da pandemia no setor do turismo, segmento em que o Pantanal sul-mato-grossense é parte do recorte espacial.

Assim, entre a pandemia da COVID-19, que se mantém durante a produção desse artigo, e um período de queimadas devastador, as águas da chuva que começaram a cair no verão oferecem um sopro de vida na maior planície de inundação do mundo, revigorando as forças de uma comunidade que resiste há séculos às intempéries às quais são submetidas.

\section{REFERÊNCIAS}

BRASIL. Lei № 14.021 de 07 de julho de 2020. Disponível em: http://www.planalto.gov.br. Acesso em: 03 de março de 2021.

BRASIL. Ministério da Economia. Secretaria Especial de Previdência e Trabalho. Cadastro Geral de Empregados e Desempregados CAGED. Base de dados online. 2020a. Disponível em: http://bi.mte.gov.br/bgcaged/caged estatistico id/cagedabela/ Acesso em: 30 novembro 2020

BRASIL. Ministério da Economia. Secretaria Especial de Previdência e Trabalho. Novo Cadastro Geral de Empregados e Desempregados - Novo CAGED. Base de dados online. 2020b. Disponível em:

https://app.powerbi.com/view?r=eyJrljoiM2ZiNzk5YzUtODU5OS00YjFmLTk1NjItNDY1M2IwMTJhOTgzliwidCI6ImNmODdjOTA4LTRhN jUtNGRIZS05MmM3LTEXZ Acesso em: 30 novembro 2020.

COSTA, Manuela Areias. A gripe espanhola em Mato Grosso e suas lições em tempos de pandemia da COVID-19. Revista Visa em Debate: Sociedade, Ciência \& Tecnologia, Rio de Janeiro, v.8, n.3, p. 26-33. ago/set. 2020.

ECOA. Pandemia se agrava no Pantanal e números crescem em dezembro. Disponível em: $<$ https://ecoa.org.br/pandemia-seagrava-no-pantanal-e-numeros-crescem-em-dezembro/ >. Acesso em: 15 fevereiro 2021.

GONÇALVES, Karoline Batista. Pantanal Transfronteiriço (Bolívia- Brasil- Paraguai) e as Áreas Protegidas: da produção de territórios às iniciativas de conservação. 2019. 314f. Tese (Doutorado em Geografia) - Faculdade de Ciências Humanas, Universidade Federal da Grande Dourados, 2019.

Instituto Brasileiro de Geografia e Estatística - (IBGE). Malha Digital do Brasil. 2017. Disponível em: https://www.ibge.gov.br/. Acesso em: 22 de fevereiro de 2021.

Instituto Brasileiro de Geografia e Estatística - IBGE. Pesquisa Mensal de Serviços - PMS. 2020. Disponível em: https://www.ibge.gov.br/estatisticas/economicas/servicos/ Acesso em: 22 de fevereiro de 2020.

MINISTÉRIO DA SAÚDE. Linha do Tempo Coronavírus. Disponível em:<https://coronavirus.saude.gov.br/linha-do-temp> Acesso em: 07 fevereiro 2021.

MINISTÉRIO DO TURISMO. Medida Provisória no 963. Disponível em:<https://www.gov.br/pt-br/noticias/viagens-eturismo/2020/05/agentes-financeiros-privados-poderao-operar-fundo-do-turismo> Acesso em: 07 fevereiro 2021.

PROJETO NOLEEDI. Disponível em: <https://www.noleedi.blogspot.com/2020/10/projeto-noleedi-responde-12-perguntas.html> Acesso em: 01 março 2021.

OBSERVATÓRIO DO TURISMO DE MATO GROSSO DO SUL. Boletim de dados turísticos de Mato Grosso do Sul 2020. Disponível em: http://www.observatorioturismo.ms.gov.br/. Acesso em: 16 fevereiro 2020.

OBSERVATÓRIO DO TURISMO DE MATO GROSSO DO SUL. Plano de retomada do turismo em Mato Grosso do Sul 2020. Disponível em:<https://www.observatorioturismo.ms.gov.br/wp-content/uploads/2020/12/Plano-de-Retomada-do-Turismo-em-Mato-Grossodo-Sul 2020.pdf>. Acesso em: 20 fevereiro 2021. 
RIBEIRO, Mara Aline. Entre cheias e vazantes: a produção de geografias no Pantanal. Campo Grande: Editora UFMS, 2015. 232p.

RIBEIRO, Mara Aline; NOVAES, Amilton Luiz. O turismo no Pantanal em tempos de pandemia da COVID-19. In: MORETTI, Edvaldo César (org.). Olhares geográficos: produção social da natureza. Porto Alegre: TotalBooks, 2020, 396p. p.175-191.

Secretaria do Estado em Saúde - SES. Boletim coronavírus COVID-19. Boletim Epidemiológico COVID-19. Disponível em: https://www.vs.saude.ms.gov.br/Geral/vigilancia-saude/vigilancia-epidemiologica/boletim-epidemiologico/covid-19/. Acesso em: 15 fevereiro 2021.

SOUZA, Mariana C. da Cunha; CAMARGO, Berta Lucia do Nascimento. Selo turismo responsável - limpo e seguro: panorama do Brasil, do estado de São Paulo e Presidente Prudente. In: III Seminário Interdisciplinar de Pesquisa Científica (edição especial). Pensar a pandemia da COVID-19 no contexto das profissões tecnológicas. Faculdade de Tecnologia - Fatec Presidente Prudente. Presidente Prudente/SP, 2020.

SPOSITO, Maria Encarnação Beltrão; GUIMARÃES, Raul Borges. Por que a circulação de pessoas tem peso na difusão da pandemia. 2020. Disponível em: <https://www2.unesp.br/portal\#!/noticia/35626/por-que-a-circulacao-de-pessoas-tempeso-na-difusao-dapandemia/>. Acesso em: 15 fevereiro 2021.

TURISMOMS. Mapa Turístico do MS. Disponível em:<http://www.turismo.ms.gov.br/conheca-ms/mapa-turistico-do-ms $>$. Acesso em: 07 fevereiro 2021.

ORGANIZAÇÃO DAS NAÇÕES UNIDAS PARA A EDUCAÇÃO, A CIÊNCIA E A CULTURA - UNESCO. Pantanal Conservation Area. s/d. Disponível em: https://whc.unesco.org/en/list/999/. Acesso em: 20 fevereiro 2021. 